\title{
Trophoblast-derived Heparanase is Not Required for Invasion
}

\author{
L.K. Harris ${ }^{\text {a }}$, P.N. Baker ${ }^{\text {a }}$, P.E.C. Brenchley ${ }^{\text {b }}$, J.D. Aplin ${ }^{\text {a,* }}$ \\ ${ }^{a}$ Maternal and Fetal Health Research Group, University of Manchester, Manchester, UK \\ ${ }^{\mathrm{b}}$ Cardiovascular and Endocrine Sciences Research Group, University of Manchester, Manchester, UK
}

Accepted 22 January 2008

\begin{abstract}
To invade the decidua and myometrium, extravillous trophoblast must degrade an assortment of extracellular matrix (ECM) components. The uterine wall is rich in heparan sulphate proteoglycans (HSPG), which interact with collagen, laminin and fibronectin, and bind a variety of growth factors. HSPG are catabolised by heparanase, an enzyme that is highly expressed in the placenta. The aim of this study was to investigate the role of heparanase in first trimester trophoblast invasion. First trimester cytotrophoblasts (CTB) were isolated by trypsin digestion followed by centrifugation on a Percoll gradient. Cells were cultured on Matrigel to promote an extravillous phenotype. Heparanase expression was studied by immunohistochemistry and confocal microscopy. Trophoblast invasion was assessed using an in vitro transwell assay. A high level of heparanase was observed in isolated first trimester trophoblast; however, a function-blocking antibody did not inhibit invasion of primary CTB or the extravillous trophoblast cell line SGHPL-4 at $21 \%$ oxygen. In contrast to cancer cells, heparanase expression was not increased following culture at $3 \%$ oxygen, and trophoblast invasion was not retarded by the blocking antibody under these conditions. Heparanase expression was observed in stromal cells and vascular endothelium in first trimester parietal decidua. Expression was evident on the cell surface and in the nucleus of trophoblast and decidual cells. In conclusion, trophoblast heparanase is not required for invasion in vitro. Its abundant expression suggests another role during pregnancy, perhaps in controlling the availability of ECM-bound growth factors or acting as a transcription factor. (C) 2008 Elsevier Ltd. All rights reserved.
\end{abstract}

Keywords: Heparanase; Pregnancy; Trophoblast; Invasion; Heparan sulphate

\section{Introduction}

Maintenance of a successful pregnancy is dependent on the ability of extravillous trophoblast to invade the decidua and myometrium and remodel the uterine spiral arteries. Degradation of extracellular matrix (ECM) components within the uterus is a prerequisite for trophoblast migration and tissue remodelling. The uterine wall is rich in heparan sulphate proteoglycans (HSPG), which interact through their glycosaminoglycan (GAG) domains with collagen, laminin and fibronectin to maintain the structure and stability of the ECM. Cleavage of heparan sulphate glycosaminoglycans (HSGAG), therefore, facilitates ECM disassembly. HSPG are present on the cell surface and in the extracellular matrix where they influence

\footnotetext{
* Corresponding author. Tel.: +44161276 6487; fax: +44 1612766134.

E-mail address: john.aplin@manchester.ac.uk (J.D. Aplin).
}

adhesion, migration and differentiation and bind a variety of growth factors, chemokines and lipoproteins [1-3]. HSGAG chains are catabolised by heparanase, an endo- $\beta$-D-glucuronidase that is highly expressed in the placenta [4,5], and by lymphocytes [6], monocytes [7], neutrophils [8] and platelets [9]. Heparanase has been studied predominantly in the context of cancer biology where its defined roles in tumour angiogenesis, invasion and metastasis are well described [10]. However, this unique enzyme has multiple roles in normal physiology and has been implicated in wound healing [11], immune surveillance [12] and hair growth [13].

Heparanase is synthesized as a $65 \mathrm{kD}$ pro-protein which is cleaved by cathepsin L-like proteases [14] to generate an active heterodimer composed of a $50 \mathrm{kD}$ and an $8 \mathrm{kD}$ subunit [15]. It is pro-angiogenic, partly because HSGAG cleavage releases angiogenic factors (VEGF, FGF-2) sequestered by HSPG in basement membranes and ECM $[1-3,16]$. It has previously been shown that human heparanase exhibits optimal activity 
at $\mathrm{pH} 4-5$ with only partial activity observed above $\mathrm{pH} 7$ $[17,18]$, suggesting additional functions for this molecule. Indeed at physiological $\mathrm{pH}$, heparanase binds to HSPG without degrading the HSGAG, and it can act as a tether for $\mathrm{CD}^{+}{ }^{+}$human T lymphocytes [18], functioning as an adhesion molecule rather than an endo- $\beta$-glucuronidase. Studies of cells transfected with green fluorescent protein (GFP)-conjugated human heparanase cDNA have shown that the enzyme is found predominantly in acidic granules and in perinuclear endosomal granules associated with the endoplasmic reticulum [19].

Heparanase has been extensively described in cancer cells, where its expression is upregulated by hypoxia and correlates with metastatic behaviour [16,20-22]. A significant correlation between enhanced heparanase mRNA [23] and protein [24] expression and shorter postoperative survival has been observed in patients with pancreatic and bladder cancer. The expression of a single extracellular enzyme has identified heparanase as a major drug target in cancer biology [25]. The role of heparanase in tissue invasion by cancer cells has been likened to extravasation of both normal and malignant bloodborne cells; after attachment to the vascular endothelium, secretion or plasma membrane expression of heparanase results in catabolism of subendothelial HSPG, which is necessary for transmural migration [26].

Extravillous trophoblasts utilise a plethora of different proteases to facilitate invasion and implantation, many of which have been extensively characterised. However, although heparanase is highly expressed in the placenta during pregnancy [4,5], the assumption has been that heparanase is involved in the mechanism of trophoblast invasion [27], despite a lack of functional evidence. In common with malignant cells, first trimester extravillous trophoblasts exist in a hypoxic environment, exhibit an invasive phenotype and demonstrate extravasation in the spiral arteries. As heparanase has been shown to be crucial for invasion and metastasis of cancer cells [20-22], we have investigated the role of heparanase in trophoblast invasion.

\section{Methods}

\subsection{Reagents}

Mouse monoclonal anti-cytokeratin-7 antibody (clone OV-TL 12/30; M 7018), mouse control $\mathrm{IgG}$, biotinylated swine anti-rabbit $\mathrm{IgG}$, biotinylated goat anti-mouse IgG, DakoCytomation A/S (Glostrup, Denmark); rabbit polyclonal antibody raised against recombinant heparanase [20]; streptavidin Alexa Fluor 488, TRITC secondary antibody, Invitrogen Corp. (Carlsbad, CA, USA); Transwell inserts, Nunc (distributed by Fisher Scientific, Loughborough, UK); Harris hematoxylin, Sigma Aldrich (Saint Louis, MO, USA); tissue culture medium and antibiotics, Cambrex (Wokingham, UK); fetal bovine serum, Gibco (distributed by Invitrogen Ltd, Paisley, UK); Matrigel, BD Discovery Labware (Bedford, MA, USA); diaminobenzidine tetrahydrochloride dehydrate (DAB), Aldrich (Milwaukee, WI, USA); XAM mounting medium, BDH (Poole, Dorset, UK); Vectashield ${ }^{\circledR}$ mounting medium, Vector Laboratories Inc. (Burlingame, CA, USA).

\subsection{Cell culture and tissue collection}

First trimester placenta and decidua (8-12 weeks gestation) were obtained at elective surgical termination of pregnancy. Informed consent was obtained for all tissue used in this study and local ethical committee approval was in place. First trimester cytotrophoblasts were isolated as previously described [28], plated onto Matrigel coated plates and cultured in 1:1 Ham's F12:DMEM. SGHPL-4 cells were cultured in Ham's F10 medium. The ovarian cancer cell line OC-MZ-6 was cultured in DMEM containing $10 \mathrm{mM}$ HEPES, $116 \mathrm{mg} / \mathrm{L}$ arginine and $36 \mathrm{mg} / \mathrm{L}$ asparagine. All media were supplemented with $10 \% \mathrm{FBS}$, L-glutamine $(2 \mathrm{mM})$, penicillin $(100 \mathrm{IU} / \mathrm{ml})$ and streptomycin $(100 \mu \mathrm{g} / \mathrm{ml})$. Cells were incubated in $95 \%$ air $/ 5 \% \mathrm{CO}_{2}$ at $37^{\circ} \mathrm{C}$, unless otherwise stated.

\subsection{Immunohistochemistry}

Primary cytotrophoblasts (CTB) were fixed with paraformaldehyde (4\% (v/v); $15 \mathrm{~min})$ and permeabilised with Triton-X 100 (0.1\% (v/v); 8 min). Primary antibodies were diluted in PBS (anti-cytokeratin-7; 1:100) and applied to CTB for $1 \mathrm{~h}$. Cells were washed three times in PBS before application of a TRITC-conjugated secondary antibody $(1: 100 ; 1 \mathrm{~h})$. Cells were then washed in PBS, incubated with a control mouse $\operatorname{IgG}(1: 200 ; 1 \mathrm{~h})$ and washed again. CTB were counterstained using an anti-heparanase antibody $(1: 100 ; 1 \mathrm{~h})$, a biotinylated swine anti-rabbit secondary antibody $(1: 200 ; 1 \mathrm{~h})$ and streptavidin Alexa Fluor $488(1: 66 ; 1 \mathrm{~h})$. After further washes, sections were mounted in Vectashield ${ }^{\circledR}$ containing DAPI.

Wax-embedded decidual tissue sections $(5 \mu \mathrm{m})$ were screened with an antibody against cytokeratin-7 to identify samples that did not contain extravillous trophoblast (parietal decidua). These sections were deparaffinised in xylene and alcohol, and microwaved for $10 \mathrm{~min}$ in sodium citrate buffer $(0.01 \mathrm{M}$; containing $0.05 \%(\mathrm{v} / \mathrm{v})$ Tween $20, \mathrm{pH} 6.0)$ to facilitate antigen unmasking. After cooling, endogenous peroxide activity was blocked by placing the slides in methanol containing $0.4 \%(\mathrm{v} / \mathrm{v}) \mathrm{HCl}$ and $0.5 \%(\mathrm{v} / \mathrm{v})$ hydrogen peroxide for $30 \mathrm{~min}$. Tissue sections were washed three times in $0.05 \mathrm{M}$ TBS and blocked with 5\% (w/v) BSA in TBS for $30 \mathrm{~min}$. Primary antibodies, diluted to the required concentration with $0.05 \mathrm{M}$ TBS (cytokeratin-7, 1:100; heparanase, 1:100; control IgG, 1:100) were applied to the tissue sections, which were incubated overnight at $4{ }^{\circ} \mathrm{C}$ in a humidity chamber. Slides were washed $(3 \times$ TBS) and the secondary antibody, diluted in TBS (biotinylated swine anti-rabbit IgG, 1:200; biotinylated goat anti-mouse IgG, 1:200), was applied for $2 \mathrm{~h}$ at room temperature. Slides were washed again $(3 \times$ TBS) and incubated with avidin peroxidase $(5 \mu \mathrm{g} / \mathrm{ml}$ in $0.125 \mathrm{M}$ TBS) for $1 \mathrm{~h}$ at room temperature. Slides were washed in TBS and incubated for 5 min with $0.05 \%(\mathrm{w} / \mathrm{v}) \mathrm{DAB}$ and $0.015 \%(\mathrm{v} / \mathrm{v})$ hydrogen peroxide. Slides were then washed in $\mathrm{dH}_{2} \mathrm{O}$, counterstained with hematoxylin, rehydrated in alcohol and xylene and mounted in XAM.

\subsection{Trans-filter migration assay}

Trophoblasts or OC-MZ-6 cells were plated onto $10 \mathrm{~mm}$ transwell inserts with $8 \mu \mathrm{m}$ pores, which were coated with a thin layer of Matrigel and placed in a 24-well plate. After the cells had adhered, the culture medium was removed and replaced with medium containing a heparanase function-blocking antibody (validated in ref. [20]) or a control rabbit IgG. Cells were incubated at $37^{\circ} \mathrm{C}$ for $24-48 \mathrm{~h}$, after which time the transwells were washed with PBS and the cells fixed in $4 \%(\mathrm{w} / \mathrm{v})$ paraformaldehyde in PBS for $15 \mathrm{~min}$. The transwells were then removed from the plates and the upper side of each insert was wiped with a cotton bud to remove the cells. The cells on the lower side of the inserts were stained using Harris hematoxylin for $15 \mathrm{~min}$. The number of cells per field was counted using a $\times 20$ objective and the results expressed as the percentage of the total number of cells, which had been cultured in parallel on a cover slip at the beginning of the experiment.

\subsection{Statistics}

Data were compared using a Wilcoxon matched pairs test. All statistical analyses were performed using GraphPad Prism software, version 4 (GraphPad Software, San Diego, CA, USA). Significance was taken as $p<0.05$. Data are presented as the mean \pm SEM from at least 3 independent experiments. 

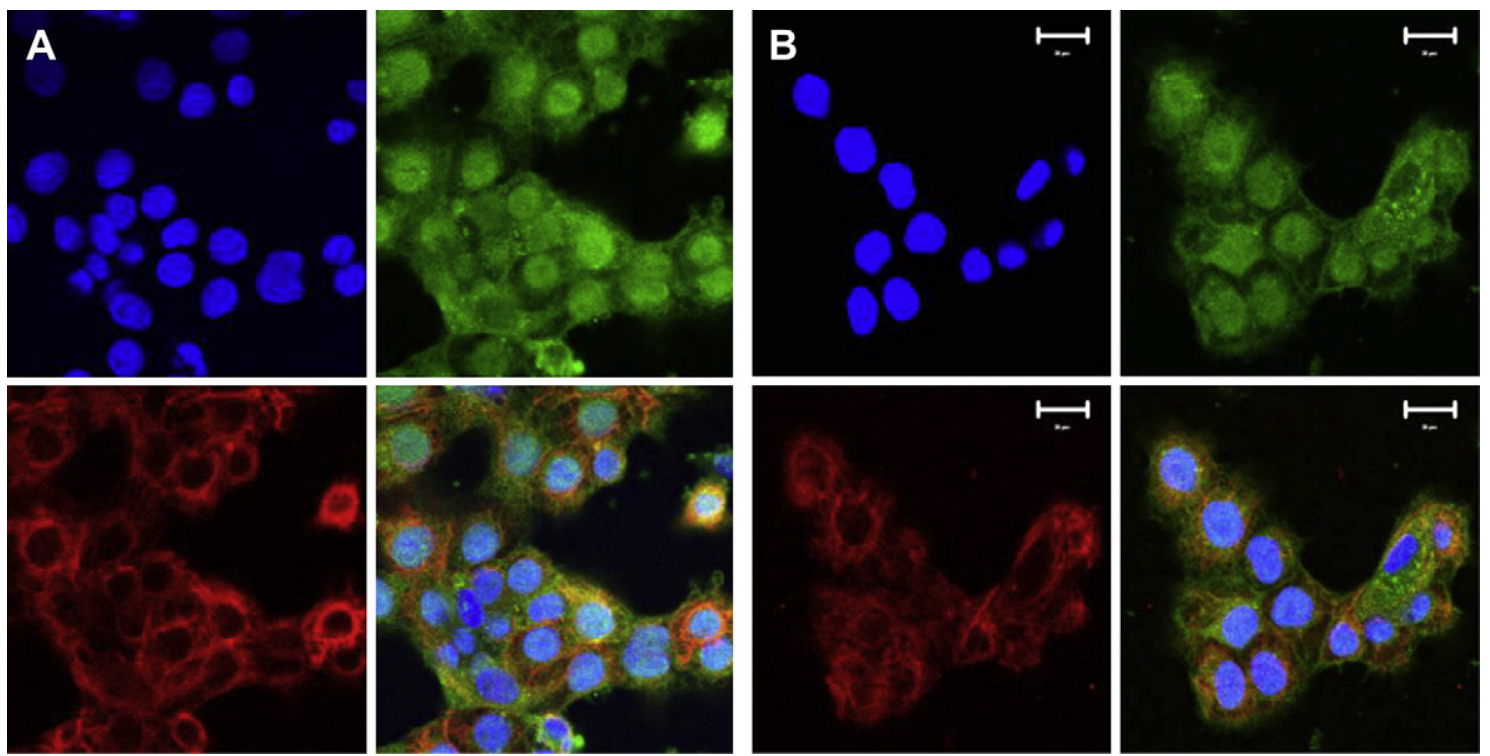

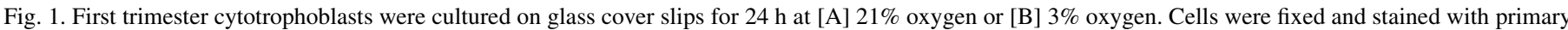

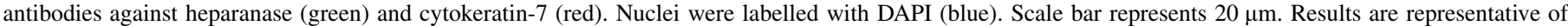
$n=4$ cytotrophoblast preparations.

\section{Results}

Heparanase expression was observed in cytokeratin-7-positive primary human first trimester cytotrophoblasts cultured at $21 \%$ oxygen (Fig. 1A). Prominent nuclear staining was evident, with expression also observed in the cytoplasm. No changes in staining intensity or cellular localisation were noted when cytotrophoblast were cultured at 3\% oxygen (Fig. 1B). Immunohistochemical staining of first trimester parietal decidua revealed that decidual stromal cells and vascular endothelial cells expressed heparanase (Figs. 2A,D). Again, immunolabelling was observed in both the cytoplasm and the nucleus of decidual cells (Figs. 2B,E). A non-specific rabbit IgG was used as a control (Figs. 2C,F).

To investigate whether trophoblast-derived heparanase is required for invasion, we studied the ability of primary human first trimester cytotrophoblast and the extravillous trophoblastderived cell line SGHPL-4, to invade a Matrigel-coated
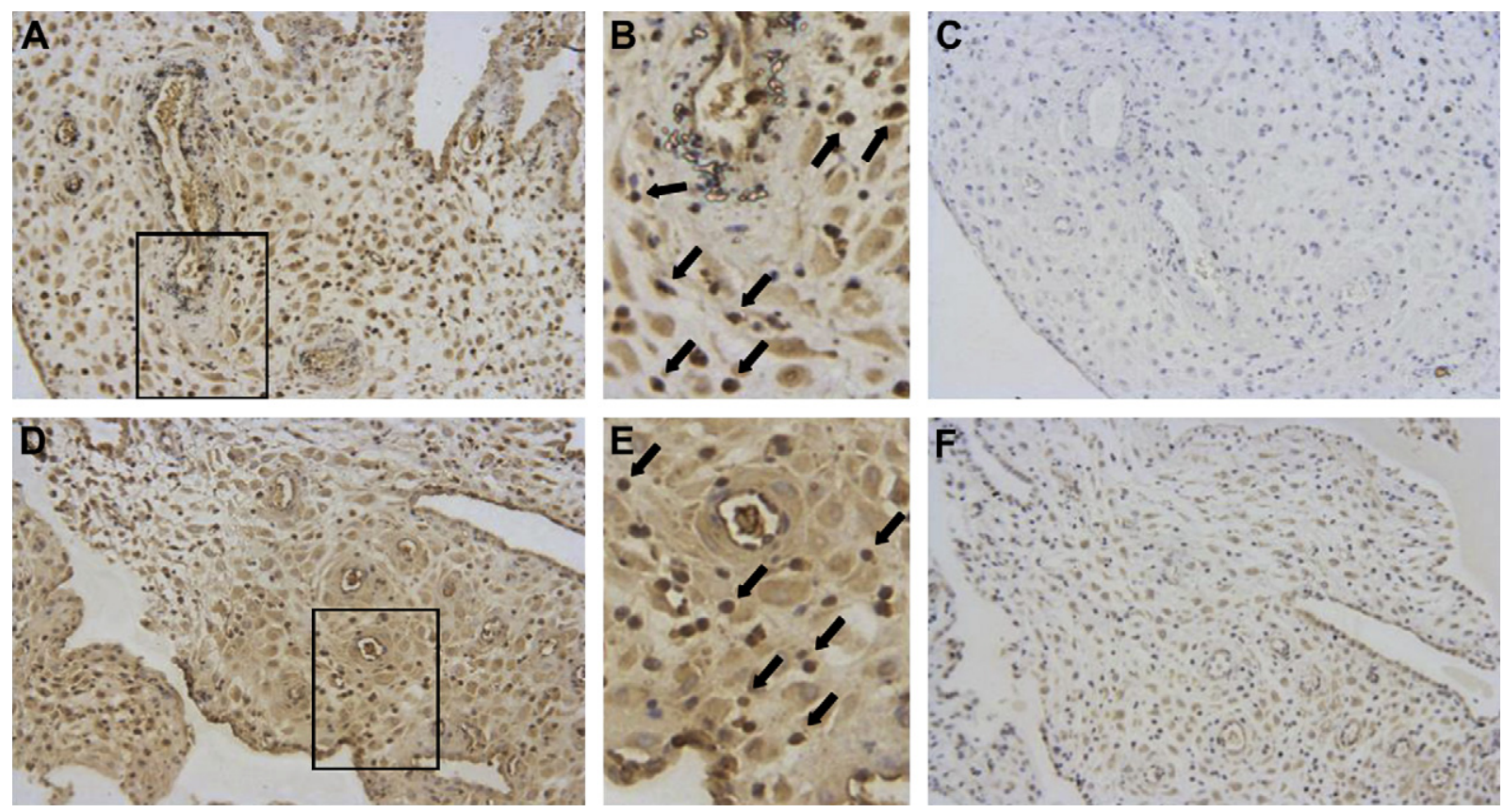

Fig. 2. First trimester parietal decidua (10 weeks gestation) was stained with an antibody against heparanase [A, B, D, E] or a control IgG [C, F]. Nuclei were counterstained with haematoxylin. Scale bar represents $100 \mu \mathrm{m}$. Arrows denote heparanase-positive nuclei. Results are representative of $n=4$ tissue samples. 
transwell filter in the presence of a heparanase function-blocking antibody. Inhibition of heparanase had no effect on the invasive capacity of first trimester cytotrophoblasts (Fig. 3A) or SGHPL-4 (Fig. 3C) cultured at $21 \%$ oxygen. Similarly, the heparanase function-blocking antibody did not inhibit trophoblast invasion at 3\% oxygen (Figs. 3B,D). To confirm that the antibody exhibited function-blocking activity, these experiments were repeated using the ovarian cancer cell line
OC-MZ-6, which requires heparanase activity for optimal invasion [20]. OC-MZ-6 cell invasion was significantly inhibited, with the percent of invading cells decreasing from $32.1 \pm 1.4$ in control cultures to $6.59 \pm 1.8$ in antibody-treated cultures $(p<0.05$; Fig. $3 \mathrm{E})$. This demonstrates that the antibody used in this study is an effective inhibitor of heparanase activity, and confirms that heparan sulphate degradation is not necessary for trophoblast invasion in vitro.
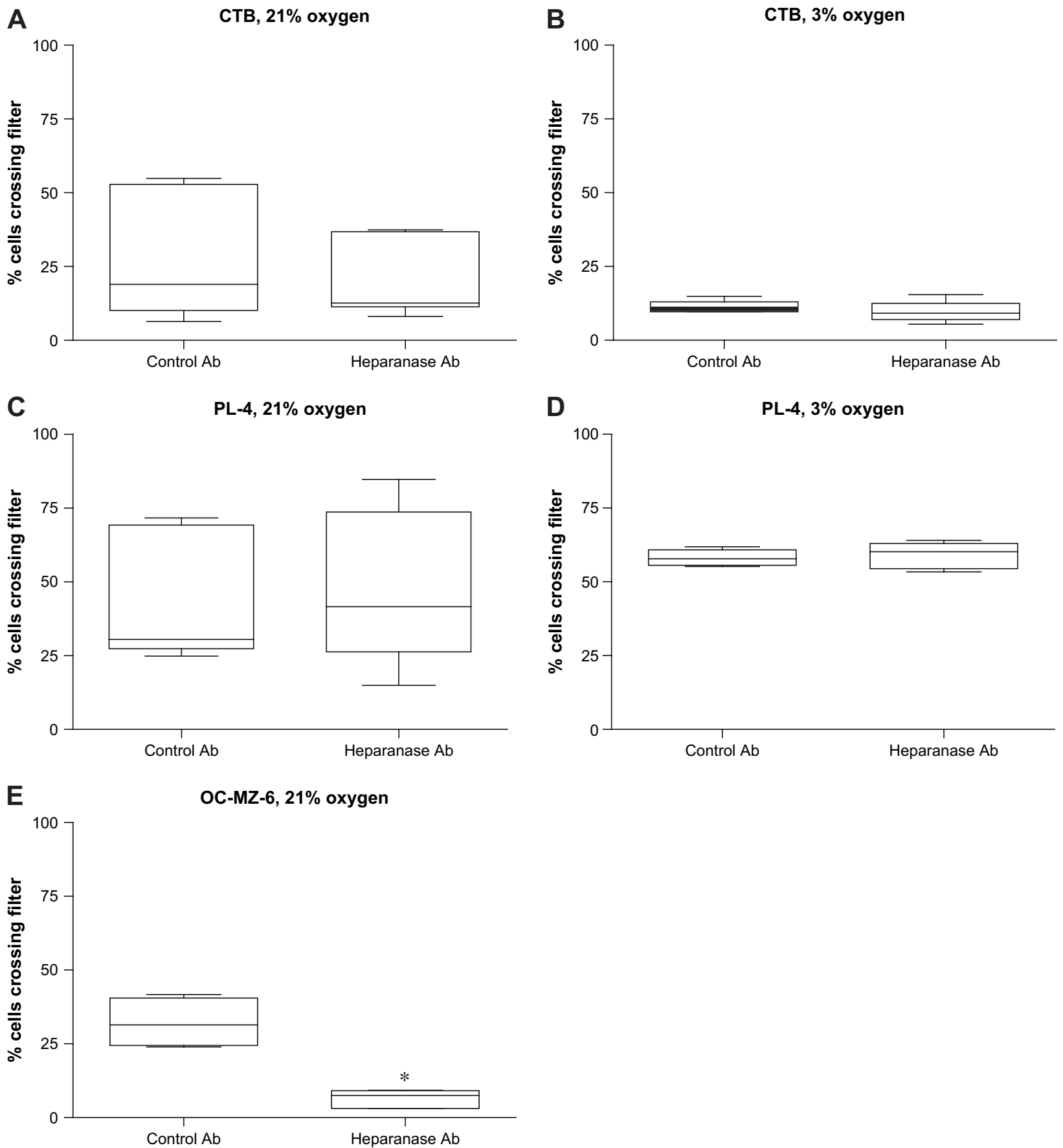

Fig. 3. First trimester cytotrophoblasts (CTB) [A, B], SGHPL-4 [C, D] or the ovarian cancer cell line OC-MZ-6 [E] were cultured in the presence of a heparanase function-blocking antibody $(100 \mu \mathrm{g} / \mathrm{ml})$ or a control $\mathrm{IgG}(100 \mu \mathrm{g} / \mathrm{ml})$ for $24 \mathrm{~h}$ (SGHPL-4, OC-MZ-6) or $48 \mathrm{~h}(\mathrm{CTB})$. The percent of trophoblasts migrating through the pores of a Matrigel-coated transwell filter was quantified by haematoxylin staining. [A] $N=16, n=4$; [B-E] $N=16, n=3$. ${ }^{*} p<0.05$, Wilcoxon matched pairs test (mean \pm SEM). 


\section{Discussion}

Here we demonstrate that trophoblast-derived heparanase is not required for invasion across a Matrigel barrier in vitro. It has previously been reported that heparanase activity does not differ between trophoblasts isolated from first trimester or term placenta [4]. As first trimester extravillous trophoblasts are much more invasive than trophoblasts isolated at term, it is unlikely that the primary role of heparanase is to mediate invasion, which has rather been shown to be dependent on the activity of proteases in the matrix metalloproteinase and plasminogen activator families [29,30]. Similarly, culture of cancer cells at low oxygen tension has previously been shown to increase heparanase activity and promote invasion [20]. During the first trimester of pregnancy, when extravillous trophoblasts are invading the decidua and myometrium, the oxygen tension in the placental bed is low. If heparanase plays a significant role in mediating trophoblast invasion at this time, it might be expected that a low oxygen environment would increase heparanase activity and promote invasion. As inhibition of heparanase function had no effect on trophoblast invasion under low oxygen conditions in vitro, this provides more evidence that heparanase is not an important mediator of invasion in vivo.

Other functions proposed for heparanase may be relevant in extravillous trophoblast. Nuclear localisation was prominently observed in first trimester CTB. Heparanase has previously been shown to act as a transcriptional regulator; translocation to the nucleus provoked differentiation of HL-60 cells [31] and COX-2 expression in primary human esophageal cancer cells [32]. Induction of COX-2 expression by leukemia inhibitory factor (LIF) has previously been shown to promote migration of another extravillous trophoblast cell line, HTR-8/SVneo [33].

There is increasing evidence that heparanase can function as an adhesion molecule, anchoring $\mathrm{CD}^{+}$human $\mathrm{T}$ lymphocytes to HSPG [18]. Over-expression of surface-associated heparanase promoted adhesion of lymphoma cells independently of its endoglycosidase activity [34]. Murine lymphoma cells over-expressing the same isoform invaded reconstituted basement membranes to a much higher extent than cells over-expressing the intracellular enzyme, demonstrated enhanced metastasis and stimulated greater angiogenesis in vivo [35], indicating that adhesion and invasion may go hand in hand. Enzymatically inactive heparanase enhances Akt signalling and stimulates PI3K- and p38-dependent migration and invasion by endothelial cells [36]. Hence, in trophoblast, it may be intracellular rather than extracellular heparanase that regulates the extent of invasion. The function-blocking antibody used in our experiments targeted secreted and surface heparanase, and further studies will be required to evaluate the effect on trophoblast function of knocking down the intracellular protein.

It has previously been shown that the phenotype of rabbit aortic smooth muscle cells (SMC) can be altered by catabolism of HSPG or by incubation with heparanase [37]. If the same is true of trophoblast-derived heparanase and spiral artery SMC, this enzyme may facilitate arterial remodelling by making SMC more sensitive to apoptotic stimuli, rather than aiding mural colonisation [26]. Heparanase may therefore be utilised indirectly to promote extravasation of trophoblast, rather than playing a direct role in matrix breakdown. Transcriptional activity of the heparanase promoter can be stimulated by estrogen [38] and the inflammatory cytokines TNF- $\alpha$ and IFN- $\gamma$ [39], which are important signalling molecules within the placental bed.

Abundant expression in both trophoblast and decidua indicates a role for heparanase at the materno-fetal interface. In mouse, heparanase is upregulated during decidualisation, and intravenous administration of the oligosaccharide inhibitor PI88 reduces implantation rates [40]. However, it does not appear necessary to fulfil the obvious role of mediating HSPG breakdown during trophoblast invasion, at least in the Matrigel assay. Instead, heparanase may be required for normal decidualisation. Further studies will be required to delineate the functions of trophoblast-derived heparanase in the placental bed.

\section{Acknowledgements}

The authors would like to thank Dr Ian Hampson for kindly donating the OC-MZ-6 cells.

\section{References}

[1] Vlodavsky I, Friedmann Y. Molecular properties and involvement of heparanase in cancer metastasis and angiogenesis. J Clin Invest 2001;108:341-7.

[2] Bernfield M, Gotte M, Park PW, Reizes O, Fitzgerald ML, Lincecum J, et al. Functions of cell surface heparan sulfate proteoglycans. Annu Rev Biochem 1999;68:729-77.

[3] Iozzo RV. Matrix proteoglycans: from molecular design to cellular function. Annu Rev Biochem 1998;67:609-52.

[4] Goshen R, Hochberg AA, Korner G, Levy E, Ishai-Michaeli R, Elkin M, et al. Purification and characterization of placental heparanase and its expression by cultured cytotrophoblasts. Mol Hum Reprod 1996;2:679-84.

[5] Haimov-Kochman R, Friedmann Y, Prus D, Goldman-Wohl DS, Greenfield C, Anteby EY, et al. Localization of heparanase in normal and pathological human placenta. Mol Hum Reprod 2002;8:566-73.

[6] Laskov R, Michaeli RI, Sharir H, Yefenof E, Vlodavsky I. Production of heparanase by normal and neoplastic murine B-lymphocytes. Int $\mathrm{J}$ Cancer 1991;47:92-8.

[7] Sewell RF, Brenchley PE, Mallick NP. Human mononuclear cells contain an endoglycosidase specific for heparan sulphate glycosaminoglycan demonstrable with the use of a specific solid-phase metabolically radiolabelled substrate. Biochem J 1989;264:777-83.

[8] Mollinedo F, Nakajima M, Llorens A, Barbosa E, Callejo S, Gajate C, et al. Major co-localization of the extracellular-matrix degradative enzymes heparanase and gelatinase in tertiary granules of human neutrophils. Biochem J 1997;327(Pt 3):917-23.

[9] Freeman C, Browne AM, Parish CR. Evidence that platelet and tumour heparanases are similar enzymes. Biochem J 1999;342(Pt 2):361-8.

[10] Vreys V, David G. Mammalian heparanase: what is the message? J Cell Mol Med 2007;11:427-52.

[11] Gingis-Velitski S, Ishai-Michaeli R, Vlodavsky I, Ilan N. Anti-heparanase monoclonal antibody enhances heparanase enzymatic activity and facilitates wound healing. Faseb J 2007; doi:10.1096/fj.1007-8866com.

[12] Lider O, Mekori YA, Miller T, Bar-Tana R, Vlodavsky I, Baharav E, et al. Inhibition of $\mathrm{T}$ lymphocyte heparanase by heparin prevents $\mathrm{T}$ cell migration and T cell-mediated immunity. Eur J Immunol 1990;20:493-9. 
[13] Zcharia E, Philp D, Edovitsky E, Aingorn H, Metzger S, Kleinman HK, et al. Heparanase regulates murine hair growth. Am J Pathol 2005; 166:999-1008.

[14] Abboud-Jarrous G, Rangini-Guetta Z, Aingorn H, Atzmon R, Elgavish S, Peretz $\mathrm{T}$, et al. Site-directed mutagenesis, proteolytic cleavage, and activation of human proheparanase. J Biol Chem 2005;280: $13568-75$

[15] Levy-Adam F, Miao HQ, Heinrikson RL, Vlodavsky I, Ilan N. Heterodimer formation is essential for heparanase enzymatic activity. Biochem Biophys Res Commun 2003;308:885-91.

[16] Ilan N, Elkin M, Vlodavsky I. Regulation, function and clinical significance of heparanase in cancer metastasis and angiogenesis. Int $\mathrm{J}$ Biochem Cell Biol 2006;38:2018-39.

[17] Toyoshima M, Nakajima M. Human heparanase. Purification, characterization, cloning, and expression. J Biol Chem 1999;274:24153-60.

[18] Gilat D, Hershkoviz R, Goldkorn I, Cahalon L, Korner G, Vlodavsky I, et al. Molecular behavior adapts to context: heparanase functions as an extracellular matrix-degrading enzyme or as a T cell adhesion molecule, depending on the local pH. J Exp Med 1995;181:1929-34.

[19] Goldshmidt O, Zcharia E, Aingorn H, Guatta-Rangini Z, Atzmon R, Michal I, et al. Expression pattern and secretion of human and chicken heparanase are determined by their signal peptide sequence. J Biol Chem 2001;276:29178-87.

[20] He X, Brenchley PE, Jayson GC, Hampson L, Davies J, Hampson IN. Hypoxia increases heparanase-dependent tumor cell invasion, which can be inhibited by antiheparanase antibodies. Cancer Res 2004;64: 3928-33.

[21] Zhang Y, Li L, Wang Y, Zhang J, Wei G, Sun Y, et al. Downregulating the expression of heparanase inhibits the invasion, angiogenesis and metastasis of human hepatocellular carcinoma. Biochem Biophys Res Commun 2007;358:124-9.

[22] Zhang ZH, Chen Y, Zhao HJ, Xie CY, Ding J, Hou YT. Silencing of heparanase by siRNA inhibits tumor metastasis and angiogenesis of human breast cancer in vitro and in vivo. Cancer Biol Ther 2007;6:587-95.

[23] Koliopanos A, Friess H, Kleeff J, Shi X, Liao Q, Pecker I, et al. Heparanase expression in primary and metastatic pancreatic cancer. Cancer Res 2001;61:4655-9.

[24] Gohji K, Hirano H, Okamoto M, Kitazawa S, Toyoshima M, Dong J, et al. Expression of three extracellular matrix degradative enzymes in bladder cancer. Int J Cancer 2001;95:295-301.

[25] McKenzie EA. Heparanase: a target for drug discovery in cancer and inflammation. Br J Pharmacol 2007;151:1-14.

[26] Vlodavsky I, Eldor A, Haimovitz-Friedman A, Matzner Y, IshaiMichaeli R, Lider O, et al. Expression of heparanase by platelets and circulating cells of the immune system: possible involvement in diapedesis and extravasation. Invasion Metastasis 1992;12:112-27.

[27] Dempsey LA, Plummer TB, Coombes SL, Platt JL. Heparanase expression in invasive trophoblasts and acute vascular damage. Glycobiology 2000;10:467-75.

[28] Cartwright JE, Kenny LC, Dash PR, Crocker IP, Aplin JD, Baker PN, et al. Trophoblast invasion of spiral arteries: a novel in vitro model. Placenta 2002;23:232-5.

[29] Cohen M, Meisser A, Bischof P. Metalloproteinases and human placental invasiveness. Placenta 2006;27:783-93.

[30] Karmakar S, Das C. Regulation of trophoblast invasion by IL-1beta and TGF-beta1. Am J Reprod Immunol 2002;48:210-9.

[31] Nobuhisa T, Naomoto Y, Okawa T, Takaoka M, Gunduz M, Motoki T, et al. Translocation of heparanase into nucleus results in cell differentiation. Cancer Sci 2007;98:535-40.

[32] Okawa T, Naomoto Y, Nobuhisa T, Takaoka M, Motoki T, Shirakawa Y, et al. Heparanase is involved in angiogenesis in esophageal cancer through induction of cyclooxygenase-2. Clin Cancer Res 2005;11:7995-8005.

[33] Horita H, Kuroda E, Hachisuga T, Kashimura M, Yamashita U. Induction of prostaglandin E2 production by leukemia inhibitory factor promotes migration of first trimester extravillous trophoblast cell line, HTR-8/ SVneo. Hum Reprod 2007;22:1801-9.

[34] Goldshmidt O, Zcharia E, Cohen M, Aingorn H, Cohen I, Nadav L, et al. Heparanase mediates cell adhesion independent of its enzymatic activity. Faseb J 2003;17:1015-25.

[35] Goldshmidt O, Zcharia E, Abramovitch R, Metzger S, Aingorn H, Friedmann $\mathrm{Y}$, et al. Cell surface expression and secretion of heparanase markedly promote tumor angiogenesis and metastasis. Proc Natl Acad Sci U S A 2002;99:10031-6.

[36] Gingis-Velitski S, Zetser A, Flugelman MY, Vlodavsky I, Ilan N. Heparanase induces endothelial cell migration via protein kinase B/Akt activation. J Biol Chem 2004;279:23536-41.

[37] Campbell JH, Rennick RE, Kalevitch SG, Campbell GR. Heparan sulfate-degrading enzymes induce modulation of smooth muscle phenotype. Exp Cell Res 1992;200:156-67.

[38] Elkin M, Cohen I, Zcharia E, Orgel A, Guatta-Rangini Z, Peretz T, et al. Regulation of heparanase gene expression by estrogen in breast cancer. Cancer Res 2003;63:8821-6.

[39] Edovitsky E, Lerner I, Zcharia E, Peretz T, Vlodavsky I, Elkin M. Role of endothelial heparanase in delayed-type hypersensitivity. Blood 2006;107:3609-16.

[40] D'Souza SS, Daikoku T, Farach-Carson MC, Carson DD. Heparanase expression and function during early pregnancy in mice. Biol Reprod 2007;77:433-41. 